\title{
Research on the Trends and Motivation of the Applied Accounting Transformation under the Background of Big Data and Internet
}

\author{
Jie Li \\ Xijing University, \\ Xi'an,Shaanxi,710123 China
}

\begin{abstract}
In this paper, we conduct research on general trends and motivation of applied accounting transformation under the background of the big data and Internet. Accounting environment is produced on which accounting theory and practice, the foundation of existence and development, also is the main standpoint of accounting study. With the constant improvement of the social information degree, the traditional social economic structure, the human mode of the production, consumption, management pattern is undergoing revolutionary change, but also changed the traditional accounting theory and practice on the accounting environment. This article mainly to the enterprise accounting environment as the background, from the enterprise organization structure, mode of production and management mode of three aspects to discuss the changes of accounting environment in network era. Our research provides the novel perspective of the issues.
\end{abstract}

Keywords: Trends and Motivation, Applied Accounting, Big Data, Internet, Transformation.

\section{Introduction}

The fierce market environment, the enterprise's internal governance relationship with the survival and development of the enterprise, internal audit system is the important content of corporate governance structure, it helps to standardize enterprise behavior and to guard against operational risks, improve the speed of the basic enterprise strategic target. So, in the new situation, enterprises should actively promote the transformation of internal audit, to achieve a methodical and specialization, internal audit work to ensure the overall economic benefits of enterprises is not affected by the loss. Therefore, under the new situation is under control of internal audit, on the general basis of significance for the development of the enterprise, to explore its internal audit transformation countermeasures for the improvement of corporate governance has important practical significance [1-2].

To deepen the financial reform, whether enterprise accounting work of the guiding ideology, to the content and methods of the work want to innovate, focuses on the following aspects. (1) The guiding principle of enterprise accounting work should have the innovation. Enterprise accounting work the switch of the guiding ideology, is the premise and foundation to realize enterprise accounting work innovation, its core is to set up the service concept, efficiency concept, market concept, legal concept. (2) The enterprise accounting personnel quality to have a new change. In order to adapt to the situation of enterprise reform and development requirements, the accounting personnel should achieve change. Accounting department should not only familiar with and master the fiscal and taxation laws and regulations, system, be familiar with and use of other economic laws and regulations, so as to better guide the work, to ensure the enterprise business activities in the orbit of legal system run orderly and healthily. (3) The traditional financial management concepts to primary accounting functions simply positioned on the accounting, that as long as to improve the quality of reports submitted even finished the task. This is completely not enough under the condition of the market, to take basic advantage of financial work dint strong this characteristic, take the market as the guidance, by means of financial management, fully actively involved in the operation of the 
business enterprise management on basis of work and management level to a new stage, to better improve economic benefit for the enterprise.

Based on the rapid development of Internet and big data, the functionality on the influences could be generally summarized as the follows. (1) Change of accounting basic assumption. First of all, the Internet environment accounting entity more wide range can be either the traditional entity enterprise, can also be a virtual company, there is no fixed location, the concept of relatively divided into fuzzy on an accounting entity. Second, under the network environment more one-time business, company expected due to the risk of network management may affected by objective factors and difficult to the control, broke the continuing operations this hypothesis. (2) The improvement of the financial reports. Due to different users of financial reports concerns each have emphasize particularly on, accounting information for financial report more levels, improve the applicability of the financial report, meet the needs of different users. (3) Accounting basic functions more optimized as the primary function of accounting for accounting and supervision, the Internet accounting to promote the development of the two functions of optimization which could be reflected from the figure one [3-4].

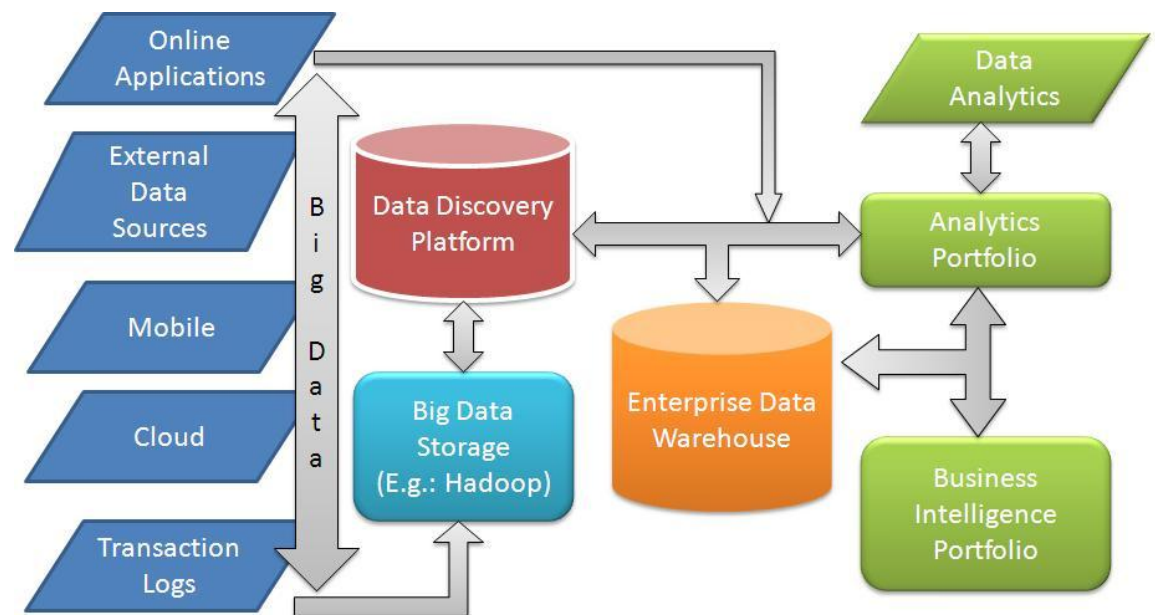

Figure 1. The Systematic Description of the Big Data Environment

In this paper, we conduct research on trends and motivation of applied accounting transformation under the background of big data and Internet. In the general process of economic development, the enterprises pay more and more attention to in management aspect, but in the process of enterprise development, the role of management accounting is not from the start was seriously, this is to make the development of management accounting after a long time. In the later sub-sections, we will list the primary perspectives of our methodology with suggestions.

\section{The Proposed Methodology}

The Big Data and Applied Accounting. Both in abroad and domestic have a number of the leading enterprises start according to the big data technology to support their management accounting work. For example, a Danish energy company management accounting to use big data to analyze investment returns, found out the most efficient for wind turbine investment location, compared to the same industry competitors, their level of return on investment is far more than the average. Management accounting is more focus on the management, but still have the basic characteristics of accounting speak in a digital, in the big data comes, we still will implement the tenet and source of management accounting, with data for decision makers to provide services, 
technical development of big data will deeply influence the management accounting work direction and work methods. In detail, we should follow the listed guidelines for modification [5].

- Provide more comprehensive accounting information. Big data environment as only provides comprehensive accounting information to meet the needs of different information users. Big data environment, only enterprise internal and external information synthesis of accounting information is the complete information. Accounting information in unstructured data will account for a large proportion. At the same time, the big data environment has caused a certain impact on the quality of accounting information. Therefore, to perfect accounting information disclosure system, to provide multi-channel information users way is very important.

- To cultivate compound accounting talents in the advance. Big data under the influence of the environment, the development of science and technology faster, but the guiding role of the people will not change, so be attention to the cultivation of the talents. Accounting personnel's focus will be shifted from daily accounting to real-time analysis and forecast of big data.

- Pay attention to the development of management accounting talents. The present enterprise financial work, still the financial accounting as the core content of work, and management accounting development relative lag, financial support for enterprise's development strategy and management to help. Financial personnel not constrained by previous knowledge of management accounting, should be from a higher altitude and broader view of responsibility, big data is a test for all financial personnel, through test can be era of qualified accountants.

- Help enterprises to realize the value transformation. Data is very valuable for enterprise, under the big data management accounting in order to realize the value of enterprise transformation, that is to say, from the original traditional management accounting to strategic management accounting, we should make full use of big data era provide data support for accounting.

The Applied Accounting and Internet. Accounting subjects also experienced the development of information revolution of catharsis, computer application in accounting has changed the traditional accounting to improve the efficiency of the accounting computerization has begun to popularize and apply. With the development of computer and network technology, its influence and the role of the accounting disciplines is also growing. Accounting subject teaching, application are also beginning to combine the network elements and adapt to society's need for accounting talents [6].

Under the age of the Internet, in order to be able to provide the more information more accurately reflect the enterprise the management and core financial situation, the existing enterprise accounting system is faced with many problems. In this case, the optimization of enterprise accounting path can neither aggressive nor lag, from construction of accounting theory, accounting category, accounting information, accounting personnel professional safety curing measures are put forward. The detailed optimization could be reflected from the listed aspects. (1) Expand the business accounting of the accounting information. We can use big data, cloud computing and other tools in the new period, to collect more comprehensive accounting information, the traditional accounting measurement of some quantitative information, such as enterprise human resources, employee training and implement after engaged in accounting to real-time calculation, reflect from the past to predict the future direction of the development, to complete the financial management from a single aspect to the planning, supply, procurement and other aspects of 
comprehensive development. (2) Perfect construction of accounting theory. New economic business, the new marketing mode, new sources of information has brought new challenges to the existing accounting work. Improve the modern enterprise accounting problems, we must want to obtain the related innovate theory.

\section{The Applied Accounting Development.} Compared with basic financial accounting, management accounting no matter from the content on the cover of or methods are flexible and scalable properties. In content, management accounting can play its planning and control methods in the field of new advantages, to establish management accounting system and it is the enterprise managers themselves can be arranged, less intervention by the government and more other relevant aspects. On the way, management accounting cannot be bound by too big to attract new method. Such as modern western management accounting is the use of strategic management in value chain analysis and competitive advantage analysis and related analysis method, to develop strategic management accounting. The development of the strategic management accounting as is the enterprise strategic management and set up information system, and provides the information of management accounting information system is the core competitiveness of important formation and mechanism of action. In the modern management, management accounting has strong vitality and development ability, it changes with the market environment, changes with the need of enterprise management and it is a powerful weapon to cultivate enterprises core competitiveness [7-8].

Under the new environment, we must change concept, objective and fair understanding of the management accounting, fully effective use of the function of core management accounting. In the method, on the development of management accounting cannot be bound by too big to introduce a new method, such as modern western management accounting is the use of strategic management in value chain analysis method and relevant analysis methods, so as to expand the strategic management accounting. In the content, on the development of management accounting for its flexibility and far more than the possibility of the financial accounting in content development, management accounting can play its planning and control in the field of new advantage. Establish a management accounting system or the system, will be less intervention by the government and other relevant aspects, this is definitely a business enterprise management authorities themselves can be arranged, and in economic management efficiency as the guidance with the motivation of enterprises to implement management accounting mainly motivation efficiency motives and interests shown in the figure two [9].

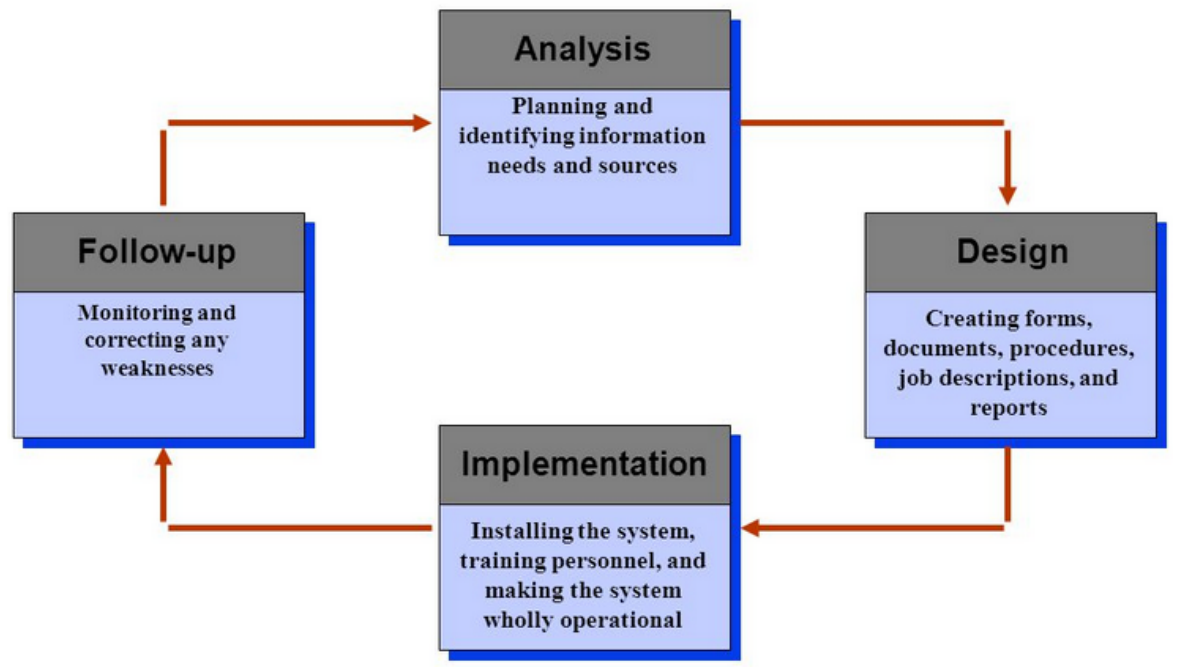

Figure 2. The Primary Developmental Components for the Applied Accounting 
The Accounting Transformation. With the rapid development of knowledge economy and the informationization, interdependence of economic and social environment of accounting development appeared more obvious changes the development of accounting itself put forward the requirements of the new era. Under the new normal economy, accounting has following characteristics: information processing integration, systematization of internal control, accounting supervision, risk early warning and real-time, etc. The economic perspective of the new normal, in order to adapt to the new era of economic transformation and structure adjustment of real need, need for accounting transformation. Transformation should be fully combined with the accounting, carefully study the current challenges facing accounting transformation, fully with the organic integration of the information technology, adhere to the people-oriented, improve the financial and accounting personnel's overall quality, integration of resources, make real-time sharing of information resources allocation mechanism, build risk oriented internal control of accounting system, to realize the transformation of accounting, giving play to the role of accounting in economy under the new normal and benefits.

In promoting the transformation of the accounting process, need to adhere to the people-oriented, knowledge, the first accounting concept. Transformation is not belong to the simple concept of the accounting or slogan, it represents the accounting adapted to the new economic environment, belongs to a kind of new accounting ideas. Operating in the field of traditional accounting that is the capital, inventory and equipment such as material resources as the center, human factors are ignored in the accounting behavior. In the new normal, talent and the knowledge has become the most important resource. Financial and accounting personnel should follow era development adhere to development of accounting theory of the knowledge first, constantly to master advanced knowledge of accounting theory and accounting practice, for new problems and new situation of economy under new normal.

\section{CONCLUSIONS}

In this paper, we conduct research on trends and motivation of applied accounting transformation under the background of the big data and Internet. The Internet era, human society is experiencing an unprecedented, dramatic change. Global competition is intense. Enterprise cross-border integration, restructuring, strategic innovation and management, create a new future. The change of management mode, marketing mode needs must management mode to cooperate. Financial management work also should from the strategic height to thinking and positioning. Our research starts from analyzing the related background to propose the novel and revised optimal transformation methodology for current accounting pattern which is innovative.

\section{References}

[1] Jun, HU Wei YANG Min ZENG. "Study on Training System of Applied Accounting Professional Talents." Journal of Hunan Finance and Economics University 3 (2012): 024.

[2] Zhang, Qinyu. "Exploration of Accounting Talent Training Mode in Higher Vocational Colleges." 2014 2nd International Conference on Education Technology and Information System (ICETIS 2014). Atlantis Press, 2014.

[3] Golden, Linda L., William W. Cooper, and Patrick L. Brockett. "Application Driven Theory: Rigorously Combining Applied and Basic Research Relevant To Accounting and Marketing." (2012).

[4] TAN, Song, and Guo-qiang WU. "The reflection on curricular system of accounting major in applied undergraduate universities." 
Journal of Huainan Normal University 4 (2012): 030.

[5] Bol, G. H., J. J. W. Lagendijk, and B. W. Raaymakers. "Virtual couch shift (VCS): accounting for patient translation and rotation by online IMRT re-optimization." Physics in medicine and biology 58.9 (2013): 2989.

[6] Arsenyeva, Olga P., et al. "Accounting for the thermal resistance of cooling water fouling in plate heat exchangers." Applied Thermal Engineering 61.1 (2013): 53-59.

[7] Starcevic, Jasminka, and Alexander E. Filippov. "Simulation of the influence of ultrasonic in-plane oscillations on dry friction accounting for stick and creep." Physical Mesomechanics 15.5-6 (2012): 330-332.

[8] Barthel, Laura. "Prevalence of Accounting Theory in Top-Ranked Undergraduate Accounting Programs." Journal of Accounting and Finance 14.4 (2014): 135.

[9] Chen, J., and D. C. Yang. "The development of the computerization of accounting." Perspectives on Accounting and Finance in China (RLE Accounting) (2013): 229. 